\title{
Stereophotogrammetry and relief photography in the assessment of foot disorders
}

\author{
ALAN D. CRAXFORD, ALISON RUTHERFORD, MARTIN S. EVANS, \\ AND COLIN PARK
}

From the University Departments of Orthopaedics, Photography and Surveying, Newcastle upon Tyne

SUMMARY Expanded polyethylene foam (Plastazote) is used in the treatment of rheumatoid, diabetic, and leprotic foot disorders. This paper describes a diagnostic use for this material. Two photographic techniques combine to give vivid and quantitative representations of foot deformities which are easily applicable to clinical use. Relief photography uses illumination to create an illusion of solidity in a 2-dimensional photograph. Stereophotogrammetry produces contour plots from stereopairs of photographs of the Plastazote footprint. After use the impressions are trimmed and slipped into the patient's shoes in the same way as any other foam insole.

The footprint has been a basic research tool for many years both in medicine and in anthropology and zoology. Studies of foot anatomy and pathophysiology have evolved in 2 distinct but interrelated directions. The first investigates form and development in a static and often qualitative way, whereas the second deals with the analysis of load and gait dynamically. A list of some of these methods ${ }^{1-10}$ is given in Table 1.

Clinically the information gained from inked imprints on paper (Figs. 1A, C, D) is simplistic,

\section{Table 1 Methods of analysis of plantar pressures}

\begin{tabular}{|c|c|}
\hline $\begin{array}{l}\text { Sac filled with plaster- } \\
\text { of-Paris } \\
\text { Combined rubber mat }+ \\
\text { glass plate }\end{array}$ & $\begin{array}{l}\text { Beely } 1882 \\
\text { Elftmann } 1934 \\
\text { Morton } 1935 \\
\text { Harding } 1942 \\
\text { Holden and Muncey } 1953 \\
\text { Barnett } 1954 \\
\text { Brand } 1963 \\
\text { Stott, Hutton and Stokes } 1973 \\
\text { Grundy } \text { et al. 1975 } \\
\text { Scranton and McMaster } 1976\end{array}$ \\
\hline
\end{tabular}

Accepted for publication 25 February 1980

Correspondence to Mr A. D. Craxford, University Department of Orthopaedics, Royal Victoria Infirmary, Newcastle upon Tyne. and the procedure is messy for the operator and patient alike. Pictures produced by mounting the camera beneath a glass plate and photographing the sole of the foot (Fig. 1B) may be adequate to describe form, but give little information about load, because the inflexibility of the glass deforms the plantar soft tissues. On the other hand the more complex forms of gait analysis are difficult to apply to the crippled patient in a clinical context and therefore remain the province of the research department.

$2 \%$ of the adult population complain of symptoms attributable to rheumatoid arthritis, and $85 \%$ of these will have foot problems some time during the course of their illness. ${ }^{11}$ There is thus a continuing need for a simple yet quantitative method of assessment of the development and progress of common foot deformities and of the results of surgical and conservative treatment.

Expanded polyethylene foam (Plastazote) has been used in clinical practice for some 10 years, firstly in the management of leprotic patients 12 and subsequently in the ambulant treatment of trophic ulcers in the diabetic foot. ${ }^{14}$ In orthopaedic practice it has a recognised place in the management of rheumatoid metatarsalgia by producing custommade total-contact insoles to fit surgical shoes. Consequently it was felt that the imprint of the foot on such an insert could form the basis of a method of assessment of deformity, the fabrication of which has already found patient acceptability and which could still be used in treatment after use. 


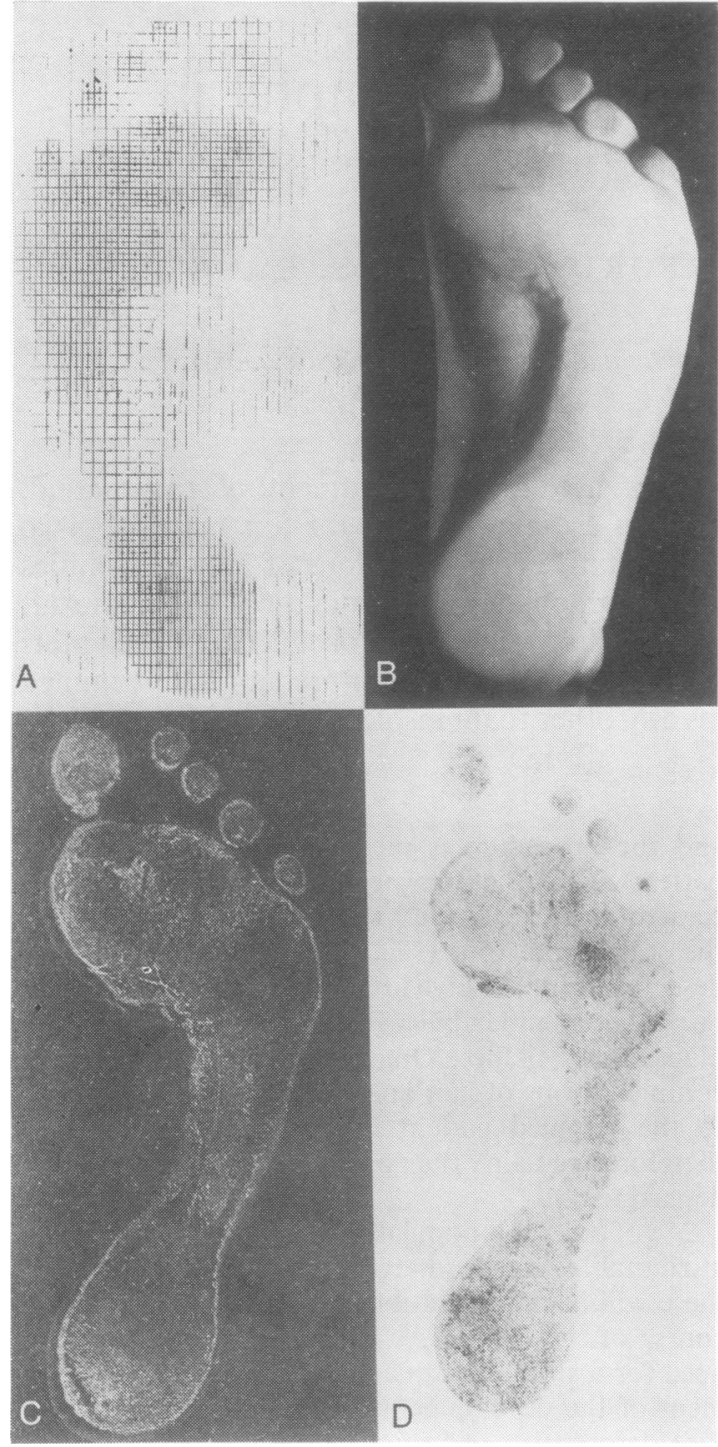

Fig. 1 Existing methods of footprinting. A. Harris ink mat. B. Sole of the foot photographed through a glass plate. C. Petroleum jelly footprint fluorescing under ultraviolet light. D. Footprint from fingerprint powder. These are from the same subject as in Fig. 2.

\section{Materials and methods}

\section{PLASTAZOTE IMPRINT}

Sheets of Plastazote $\frac{3}{4}$ inch $(20 \mathrm{~mm})$ thick are used in a standardised way to make the impression. This involves placing the foot directly on the centre of the sheet, keeping the foot and ankle at a right-angle, and asking the patient to look straight ahead. The patient takes full weight on each foot in turn, steadying his balance between 2 firm supports. The completed impression is then subjected to 2 different processes.

\section{RELIEF PHOTOGRAPH}

The insole is placed under the glass plate of a standard photographic copying table (in this project a Leitz Reprovit). The camera is mounted directly above the table, and the Plastazote is illuminated from one side only. The angle of incidence is $45^{\circ}$. Ilford $35 \mathrm{~mm}$ Pan F film is used, exposed for 7 seconds at an aperture of $\mathrm{f} 11$ and developed in Ilford Microphen for $4 \frac{1}{2}$ minutes at $23^{\circ} \mathrm{C}\left(73^{\circ} \mathrm{F}\right)$. Monochrome emprints are produced which give the appearance of the foot in relief rather than as a depression.

\section{STEREOPHOTOGRAMMETRIC RECORD}

Stereophotogrammetry is the science of dimensional analysis of photographs using stereoscopic methods and equipment. It is a standard procedure used by land surveyors in the preparation of topographic maps from aerial photographs. The technique, which is noninvasive, has been used in a number of applications in medicine, orthopaedics, and oral surgery. ${ }^{15}$

The Plastazote impression is photographed with $a^{a}$ stereometric camera. This comprises 2 identical cameras of known inner orientation separated by a known distance which produce a stereopair of photographs. Synchronisation is by electronic flash, which is used to improve illumination. Ektachrome $X$ colour reversal film is used for photography. Prior to exposure the impression is sprinkled with coloured confetti to add texture to the uniform surface.

After processing the stereopair is orientated in a Wild A7 stereoplotter to form a 3-dimensional model of the footprint at a known scale. This is then probed with a measuring mark which can be moved by hand and foot controls in 3 mutually perpendicular directions relative to the model and which can be brought to rest on any point on its surface. Movement of the mark is linked to a drawing pencil which allows the plotting of contour lines to present a graphical display of the shape of the footprint. The contour plots are produced lifesize and the contour interval is $1 \mathrm{~mm}$.

\section{Results}

\section{REPRESENTATIVE ILLUSTRATIONS}

Fig. 2 shows the relief photograph and stereophotogrammetric plot of a normal foot. They demonstrate the expected pattern of pressure across the metatarsal heads with increased loading through the 
hallux. ${ }^{16} 17$ All 5 toes touch the ground, and the contour lines indicate a well-developed arch.

The appearance of the foot in a patient with rheumatoid arthritis and localised metatarsalgia is shown in Fig. 3. There is soft tissue swelling over the
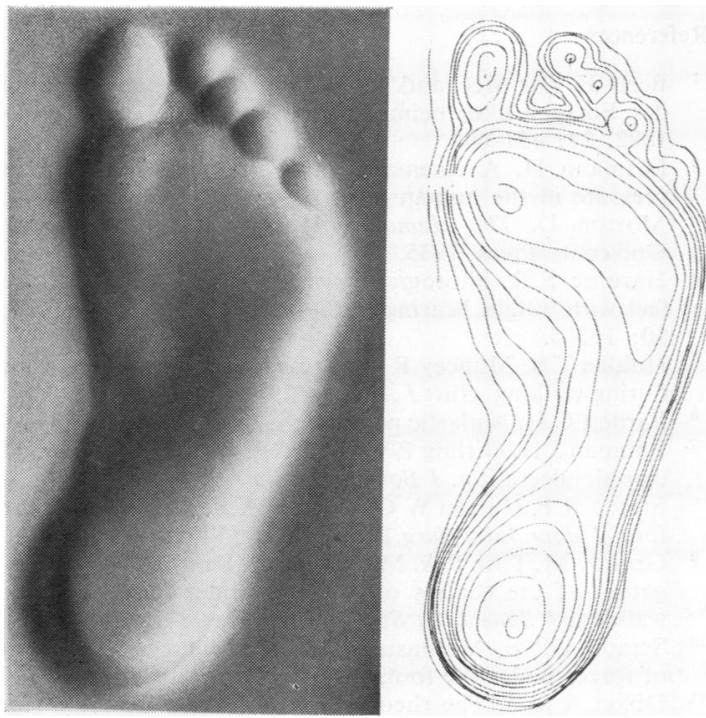

Fig. 2. Relief photograph of a normal foot, with stereophotogrammetric plot.
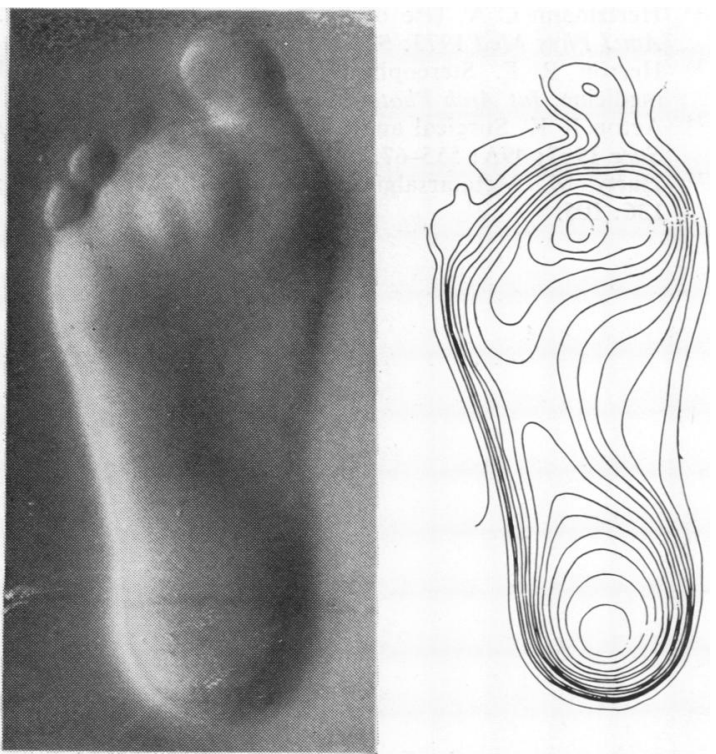

Fig. 3A. Photograph of prolapsed metatarsal heads with concommitant dislocation of the metatarsophalangeal joints, with stereophotogrammetric plot.
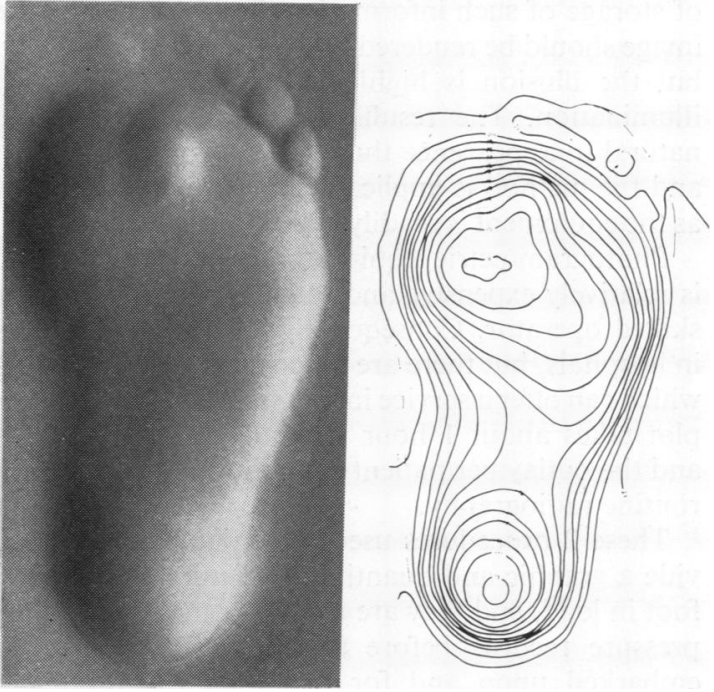

Fig. 4A. Photograph of a case of recurrent metatarsalgia following forefoot arthroplasty, with stereophotogrammetric plot.

affected area and the metatarsal heads are prolapsed into the sole. There is dorsal dislocation of the second and third metatarsophalangeal joints, which is seen by the absence of an impression of the relevant toes. The abnormal loading across the metatarsal heads is plainly seen on the contour plot.

Fig. 4 shows a foot that has suffered from a recurrence of metatarsalgia some time after apparently successful surgery. All the metatarsals are short, though the second one is relatively longer than the rest and is markedly prominent. The site of abnormal weight bearing arises more proximally in the sole than the symptoms suggest. The inner 3 toes are functionless.

\section{Discussion}

Because Plastazote is already used in the treatment of foot disorders, its use as a diagnostic tool in this way does not require any alteration for its application to disabled patients. Some authorities have objected to the production of insoles directly from the foot, ${ }^{14}$ preferring to imprint the material with a plaster cast which allows the insole to be moulded to the shape of the borders of the foot. However, this method requires a flat impression to produce the maximum weight-bearing deformity. There has been no complaint of excessive heat in this series, which so far includes over $\mathbf{3 0 0}$ footprints.

The ability to see the sole of the foot in load is invaluable in the clinical management of deformities, and the relief photograph provides the ideal method 
of storage of such information. The reason why the image should be rendered as a relief remains unclear, but the illusion is highlighted by the use of side illumination. The results are more dramatic and natural in appearance than those from the ink mat, and the method is applicable in every hospital unit, as the equipment is readily available and inexpensive.

Photogrammetric equipment on the other hand is relatively expensive and requires the services of a skilled operator. Consequently it is rarely available in hospitals, but there are a number of organisations which can offer a service in this respect. Each contour plot takes about 1 hour to photograph and draw, and the outlay per patient compares favourably with routine radiography.

These 2 procedures used in conjunction can provide a graphic and quantitative picture of the static foot in load, and they are useful for making baseline pressure records before a course of treatment is embarked upon and for reviewing the results of surgery. They will delineate the extent of areas of abnormal pressure which are of importance before revisional surgery is undertaken. Because the method is noninvasive and easy to use, these procedures are invaluable for illuminating the natural history of the deforming foot by repeated examinations over a period of time. They are also being used by this research team in an endeavour to rationalise the design of surgical shoes.

The impression is easily trimmed and buffed to fit the patient's shoes to produce custom-made totalcontact weight-bearing insoles once photography has been carried out. If this is not required, the sheet may be reheated and used again.

This paper is based on an award-winning presentation given at the IXth European Congress of Rheumatology at Wiesbaden, West Germany, September 1979.
The authors are indebted to Professor J. Stevens and Dr W. Carson Dick, University Departments of Orthopaedics and Rheumatology, for the advice in the preparation and revision of the manuscript.

Plastazote is the registered trade mark of Messrs Bakelite Xylonite Ltd, and is distributed for hospital use by Messrs T. J. Smith and Nephew, Welwyn Garden City, England.

\section{References}

1 Beely F. Zur Mechanik des Stehens: Über die Bedeitung des Fussgewölkes beim Stehen. Langenbecks Arch Chir 1882, 27: 457-68.

2 Elftmann H. A cinematic study of the distribution of pressure in the human foot. Anat Rec 1934; 59: 481-7.

3 Morton D. The Human Foot. New York: Columbia University Press, 1935.

4 Harding F R. Photographing the plantar surface of the feet with weight bearing. J Biol Photographers Ass 1942; 10: 113-5.

5 Holden T S, Muncey R W. Pressures on the human foot during walking. Aust J Appl Sci 1953; 4: 405-9.

- Barnett C H. A plastic pedograph. Lancet 1954; ii: 273.

7 Bauman J H, Girling P W, Brand P. Plantar pressure and trophic ulceration. J Bone Joint Surg 1963; 45B: 652-71.

8 Stott J R R Hutton W C, Stokes I A F. Forces under the foot. J Bone Joint Surg 1973; 55B: 335-44.

9 Grundy M, Tosh P A, McLeish R D, Smidt L. An investigation of the centres of pressure under the foot while walking. J Bone Joint Surg 1975; 57B: 98-103.

10 Scranton P E, McMaster J H. Momentary distributio of forces under the foot. J Biocmeh 1976 ; 9: 45-8.

11 Dixon A St J. The rheumatoid foot. Mod Trends Rheu matol $1971 ; 2$ : 158-73.

12 Tuck $\mathrm{W} \mathbf{H}$. The use of Plastazote to accommodate deformities in Hansen's disease. Lepr Rev 1969; 40: 171-3.

13 Mondl A M, Gardiner J, Bissett J. The use of Plastazote in footwear for leprosy patients. Lepr Rev 1969; 40: 177-81.

14 Hertzmann C A. Use of Plastazote in foot disabilities. Am J Phys Med 1973; 52: 289-303.

15 Herron R E. Stereophotogrammetry in biology and medicine. Int Arch Photogrammetry 1972; 19 : 5.

16 Acton R K. Surgical anatomy of the foot. J Bone Joint Surg 1967; 49A: 555-67.

17 Harty M. Metatarsalgia. Surg Gynecol Obstet 1973; 136: 105 . 